cryolitic formations. Data suggest the establishment of an exceptional blockage of winter atmospheric circulation in Central Asia for almost two centuries, which must correspond to some climatic events of global dimension. Steppes were reduced and human habits become more sedentary, with primitive agricultural practices in the piedmont fans (Wusun culture).

\section{Middle Subatlantic; Early and Mid Middle Ages (1800-800 BP)}

Plains and mountains were characterized by cold-wet conditions until 1000 BP when conditions close to modern were established. Continentality indexes remained high with cold-dry winters. The Northern Tien Shan saw a catastrophic degradation of ice deposits from which they never recovered. Balkhash water levels decreased to a minimum of 339 $m$ around 800 BP. Human geography saw the expansion of agricultural activities together with the spread of irrigation practices, proto-urbanization along river courses and the blossoming of the northern branch of the Silk Road (late Wusun and Turkic periods).

\section{Late Subatlantic; Middle and Late Middle Ages (800-200 BP)}

Climate became cooler and wetter than either the former period or the modern climate. Moderate advances of ice occurred. The plains reached a minimum temperature around $550 \mathrm{BP}$, the mountains around 250 BP. Balkhash water levels continued to rise until a peak of $344 \mathrm{~m}$ was reached in $1910 \mathrm{AD}$. A conversion to pastoralist practices and nomadic habits took place. Most likely this was favored by the reestablishment of climatic conditions similar to those of the Early Iron Period but also by political military events and the crisis in the Silk Road trade (Mongol and early Kazakh periods). After 200 BP, climatic conditions tended progressively towards the warmer and drier conditions of modern times.

\section{REFERENCES}

Aubekerov B.J., 1993: Stratigraphy and paleogeography of the plain zones of Kazakhstan during the late pleistocene and holocene. In: Development of landscape and climate of Northern Asia, late pleistocene and holocene. Vol 1, pp101-110. Nauka, Moscow (in Russian).

Aubekerov B.J., Sala R., Nigmatova S. and Shakupova S., 2001: Paleoclimatic conditions in the arid zones of Semirechie during the Bronze and Early Iron epochs. In: Natural and social problems of geography of arid regions, pp 26-33. KAZNY, Almaty (in Russian).

Kremenezki K.B. and Tarasov P.E., 1994: Paleogeographic study of Kazakhstan during the holocene: palinology and stratigraphy. Nauka, pp151-159. Moscow (in Russian).

Pakomov M.M. and Chupina L.H., 1973: The general formation laws of the modern spore-pollen spectra in the eastern mountains of Central Asia. In: Trudi, Mesdunarodnie Palinologiskaya Conferentsia. Moscow (in Russian).

Tarasov P.E. et. Al., 1992: Climatic fluctuation in the steppe zone of Kazakhstan during holocene, based on data from spore-pollen analyses. Vestnik MGU series 5, Geography n 1-94, pp 99-103. Moscow (in Russian).

\title{
Holocene Ocean-Climate Variations in the Gulf of California, Mexico
}

\author{
Robert Douglas ${ }^{1}$, Oscar Gonzalez-Yajimovich ${ }^{1,2}$, Donn Gorsline ${ }^{1}$, Francisca Staines-Urias ${ }^{1,2}$ and J. Fernando Arreola-Hernandez ${ }^{1,3}$ \\ ${ }^{1}$ Department of Earth Sciences, University of Southern California, Los Angeles, California 90089-0740, USA; rdouglas@usc.edu; \\ 2 Facultad de Ciencias Marinas, Universidad Autonoma de Baja California, Ensenada, Mexico; \\ ${ }^{3}$ Centro Interdisciplinario de Ciencias Marinas-Instituto Politecnico Nacional, La Paz, Mexico.
}

Despite complexities, the Gulf of California can be considered an ocean-climate system in which primary productivity and sedimentation are largely controlled by seasonal monsoon winds. It offers an ideal model for exploring the oceanclimate variations in which decadal to millennial scale changes can be reconstructed from sediment cores that sample the latest Pleistocene and Holocene.

During winter months, strong NW winds flow down the length of the Gulf, cooling surface waters, and initiating surface mixing and Ekman transport along the eastern margin and the development of a major winter-spring bloom of diatoms. Primary productivity rates in the central Gulf can exceed $4 \mathrm{gC} / \mathrm{m}^{2} /$ day during the winter season, making the Gulf one of the more productive sites in the global ocean. The winds also transport large quantities of dust, which together with the flux

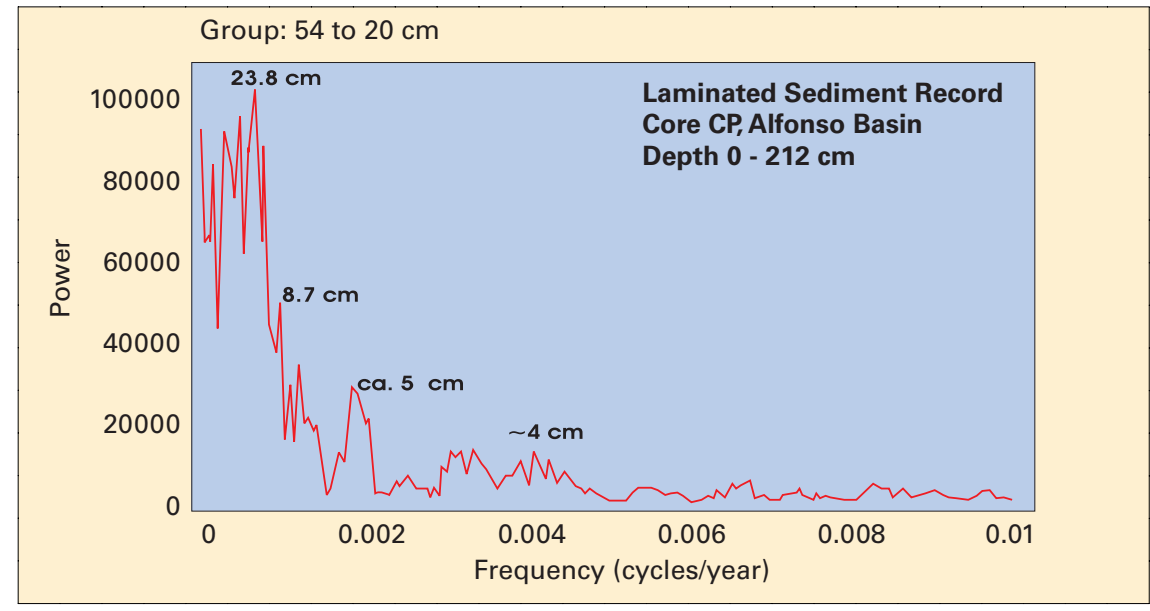

Figure 1: Spectra of peaks of variability found in laminated sediments and carbonate content in core BAP96-CP, Alfonso Basin (MTM method). Major periodicities are given in Table 1.

of biogenic debris contribute to the clayey mud that predominates in slope and basin sediments.

During summer months, winds are from the SE, a strong thermocline develops, which reduces nutrient transfer and there is a decline in primary productivity. The biogenic flux to the seafloor is dominated by pelagic carbonate and so-called "shade floras", matforming and large centric diatoms which grow in the nutricline. The mats are dumped to the seafloor in late autumn or early winter with the onset of the NW winds. In the central and eastern Gulf, these matforming diatoms contribute to the formation of sediment laminations. The SE winds bring summer storms 


\section{Science Highlights}

and, except for El Niño years, most of the precipitation in the Gulf falls between July and October.

The deep-water sediment record in the Gulf reflects the monsoon control of biogenic and terrigenous input, especially in the hemipelagic sediments of the slopes. In the Gulf, the Oxygen Minimum Zone (OMZ) typically ranges between about 300 and $1000 \mathrm{~m}$ and where it intersects the seafloor, bottom-water dissolved oxygen concentrations are $<0.5 \mathrm{ml} / \mathrm{l}$ to zero. Laminated varves accumulate in these depositional environments. Preserved within the laminations is a record of the monsoon-induced seasonal variations in production and sedimentation as well as longer-term ocean-climate variations.

Holocene sediments in the Gulf of California are biogenic silica- and organic carbon-rich, generally carbonate poor and within the $\mathrm{OMZ}$, intensely laminated. In contrast, late Pleistocene and Younger Dryas sediments are carbonate-rich, biogenic silica-poor and typically bioturbated.

Recent multi-institutional investigations have emphasized different approaches to producing high-resolution (10-30 years/sample) Holocene records. John Barron and

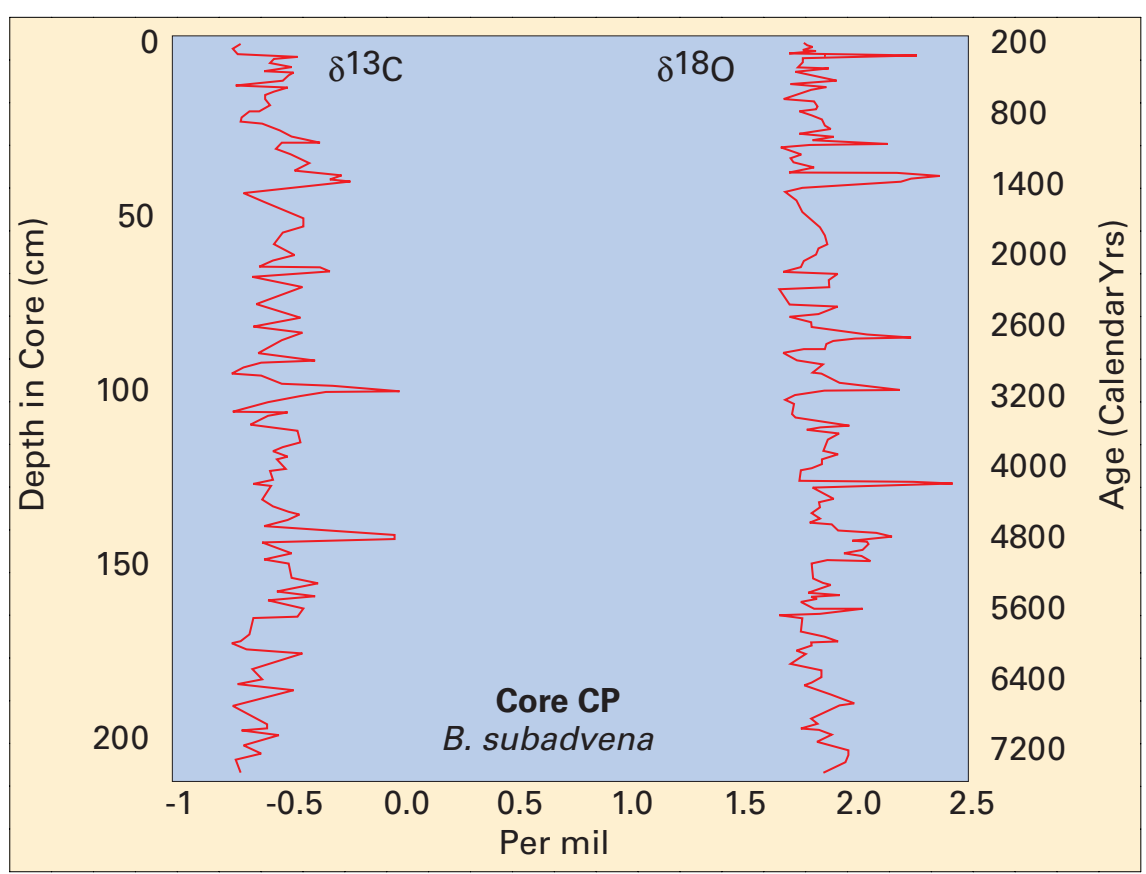

Figure 2: Stable isotope record of Bolivina subadvena in a core collected near the center of Alfonso Basin (core BAP96-CP; $1 \mathrm{~cm}$ sample interval). Age-depth model based on excess ${ }^{210} \mathrm{~Pb}$ profiles and corrected radiocarbon dates. Based on recently collected multi-cores from the same site, we estimate that about 200 years is missing from the top of core CP.
Table 1: Spectral peaks of variability derived from separate analyses of the laminated sediments and carbonate record in core BAP96-CP in Alfonso Basin (MTM method). Ages estimated using average sedimentation rates derived from $A M S^{14} \mathrm{C}$ age-depth model.

\begin{tabular}{|c|c|c|c|c|c|}
\hline \multicolumn{4}{|c|}{ Laminated Sediment } & \multirow{2}{*}{$\begin{array}{c}\text { Carbonate } \\
0-212 \mathrm{~cm}\end{array}$} & \multirow{2}{*}{$\begin{array}{c}\text { Periodicities } \\
\text { approx.age }\end{array}$} \\
\hline $0-212 \mathrm{~cm}$ & $0-150 \mathrm{~cm}$ & $150-2$ & $17-116 \mathrm{~cm}$ & & \\
\hline 54 & 42.8 & & & 40 & $1480 \pm 100$ \\
\hline 23.8 & 22.6 & 22.4 & & 27.3 & $898 \pm 82$ \\
\hline 16.4 & 18.7 & 16.4 & & & $615 \pm 44$ \\
\hline 8.7 & 5.5 & 7.6 & 8.2 & 7.8 & $300 \pm 20$ \\
\hline 5 & 4.9 & & & 5.7 & $192 \pm 20$ \\
\hline 4 & 4 & & 3.7 & 4.3 & $144 \pm 18$ \\
\hline
\end{tabular}

colleagues of the U.S. Geological Survey (Menlo Park, USA) have focused on the diatom-rich, carbonate-poor sediments in cores DSDP 480 and JPC56 in Guaymas Basin (central area of the Gulf), while our group (listed above) has focused on the sediments microfabrics, stable isotopes and carbonate microfossils in the more carbonate-rich sediments of the western Gulf and Alfonso Basin (mouth of the Gulf). These investigations have produced complementary results and suggest that the shifts in the Holocene Gulf are ultimately the result of an intensification and seasonal shift in the NW monsoon winds that control the patterns of upwelling, and that the changes are paced by climate rhythms that have strong modes of about $200 \mathrm{yr}, 300 \mathrm{yr}$ and $1500 \mathrm{yr}$.
In Guaymas Basin, an increase in the production of biogenic silica and changes in the relative abundance of diatom floras suggest shifts in the seasonal intensity of upwelling, with spring upwelling dominating in the early and late Holocene and winter upwelling dominating in the mid Holocene and today (Barron, et al., 2000; Barron, 2003). After about $6 \mathrm{ka}$, spring upwelling increased on the mainland side of the Gulf. Coincident with the shift in upwelling, the carbonate content of Guaymas Basin shifted, with more intense dissolution in sediments in the eastern Gulf leading to very low carbonate content, generally beneath the main upwelling centers.

Alfonso Basin is situated near the junction of the Gulf of California and the open Pacific Ocean, which places it in a sensitive location to record the variation in the monsoon-driven climate in the Gulf, as well as the larger-scale climate variations occurring in the Pacific. The basin is silled (depth ca. $250 \mathrm{~m}$ ), filled with dysoxic-anoxic waters and accumulating laminated sediments on the basin floor. Cores collected from the basin floor have recovered most of the Holocene (7700 yBP) based on AMS radiocarbon dates and varve counts produced from digitally scanned Xradiograph positives. All cores were sampled at $1 \mathrm{~cm}$ intervals (approx. 15-35 years/sample).

Spectral analysis of the laminated stratigraphy and carbonate in core BAP96-CP was used to identify millennial and centennial peaks of climate variability (Douglas, et al., 2002) (Fig. 1). For the microfabrics analysis, gray scale images were produced from X-radiograph prints, digitized and converted to pixel number and analyzed using 
the multi-tapered Method (MTM). No filters were applied. This produced a continuous, millimeter-scale record. The resulting power spectra frequency peaks were converted to calendar years based on the agedepth model. Because of variations in the microfabric record (density of laminations, microburrows, flood layers), spectral peaks were calculated separately for three cores and for selected intervals within the cores. The results were the same for all cores.

Strong peaks of variability were found with periodicities at about 150 yrs (144 \pm 18 yrs), 200 yrs $(192 \pm 20$ yrs) and 300 yrs $(300 \pm 20$ yrs $)$ (Table 1). These are associated with productivity/dissolution cycles in the carbonate record. All these periodicities are present prior to 3200 yBP but the 300-year cycle dominates in the latest Holocene. Similar productivity pulses have been identified by Gladys Bernal-Franco (2001) in the biogenic record in La Paz Basin on a 330-year period. We suspect that the centennial variability is related to variations in solar radiation identified in radiocarbon fluctuations in tree rings and ${ }^{10} \mathrm{Be}$ records. Millennial scale variations at $900 \mathrm{yrs}$ (898 \pm 82 yrs) and 1500 yrs $(1480 \pm 100$ yrs) are strong in both the carbonate and sediment lamination records.

Stable isotopes measured on the benthic foraminifera Bolivina subadvena in Alfonso Basin (core BAP96$\mathrm{CP}$ ) exhibit small variation through the 7700 yBP record, except in the ${ }^{18} \mathrm{O}$ record. Beginning about $6 \mathrm{ka}$, the record is punctuated with a series of short-term excursions or events of 0.5 to $0.9 \%$, the largest of which occurs between 5200 and 1400 yBP (Fig. 2). The events signal a turnover in the water-mass in the basin and replacement by either much colder or higher salinity water. The basin sill is located at ca. $250 \mathrm{~m}$ depth, near the present-day lower boundary of Central Gulf Water-a high salinity water-mass produced by evaporation in the northern Gulf of California during winter months - and is advected at shallow depths along the western margin depth of the Gulf towards the mouth. We believe the most likely explanation for the isotopic excursions is basin turnover, when increased production of Central Gulf Water flooded the basin (Douglas and Staines-Urias, in press). If this interpretation is correct, the isotopic excursions record periods of intensified NW winds in the mid and late Holocene.

\section{REFERENCES}

Barron, J., Bukry, D. and Bischoff, J., 2003: A 2000 yr Iong Record of Climate From the Gulf of California. Proceedings of the 19th Pacific Climate Workshop, PACLIM 2002, Technical Report 69 of the Interagency Ecological Program for the San Francisco Estuary, $15 \mathrm{pp}$

Barron, J., Bukry, D. and Bischoff, J., 2003: High-resolution Paleoceanography of the Guaymas Basin, Gulf of California, during the past 15,000 years. Paleoceanography, in press.

Bernal Franco, G. R., 2001: Registro Paleoceanografico en los sedimentos laminados de la cuenca de La Paz, margen occidental del bajo Golfo de California. tesis Doctoral, Centro de Investigacion Cientifica y Educacion Superior de Ensenada (CICESE), Mexico, $110 \mathrm{pp}$

Douglas, R., Gorsline, D., Grippo, A, Granados, I. and Gonzalez-Yajimovich, 0., 2002: Holocene ocean-climate variations in Alfonso Basin, Gulf of California, Mexico. In, West, G. J. and Buffaloe, L. (eds.), Proceedings of the18th Pacific climate Workshop, PACLIM 2001, Technical Report 68 of the Interagency Ecological Program for San Francisco Estuary, pp. 7-20.

Douglas, R. and Staines-Urias, F., Stable isotopic evidence for variation in the production of Central Gulf Water-Mass and turnover in Alfonso Basin during the Holocene, Ciencias Marinas, in press.

\section{Climate and the Maya}

Gerald H. Haug ${ }^{1}$, Detlef Günther ${ }^{2}$, Larry C. Peterson ${ }^{3}$, Daniel M. Sigman ${ }^{4}$, Konrad A. Hughen ${ }^{5}$, Beat Aeschlimann ${ }^{2}$

${ }^{1}$ Geoforschungszentrum Potsdam, D-14473 Potsdam, Germany; haug@gfz-ptsdam.de

2Department of Chemistry, ETH, CH-8092 Zürich, Switzerland

${ }^{3}$ Rosenstiel School of Marine and Atmospheric Science, University of Miami, Miami, FL 33149, USA

${ }^{4}$ Department of Geosciences, Princeton University, Princeton, NJ 08544, USA

${ }^{5}$ Woods Hole Oceanographic Institution, Woods Hole, MA 02543, USA

The relative stability of Holocene climate, at least when compared to the rapid, large-amplitude climate excursions of the last ice age, has contributed to a view that the road to modern human civilization has been little affected by climate road-bumps. However, significant variations in regional Holocene climate have now been recognized, with some having had clear societal impacts. Here we summarize recently reported new data from the annually laminated sediment record of the anoxic $\mathrm{Ca}$ riaco Basin off northern Venezuela, a now well-known paleoclimate archive. Using a new method for the measurement of bulk sediment chemistry, we have been able to develop a record of varying river- derived inputs to Cariaco Basin with roughly bimonthly resolution $(50 \mu \mathrm{m}$ sample spacing) for the period $A D$ 700 to 950 (Haug et al., 2003). Terminal Collapse of the Classic Maya civilization in the lowlands of the Yucatan Peninsula in Mesoamerica occurred during this time, one of the most dramatic events in human history (Fig. 1). Our new record of riverine input to Ocean Drilling Program (ODP) Site 1002 shows in unprecedented detail evidence of a link between regional drought and the demise of the Maya culture.

Paired light-dark laminations preserved in the anoxic, non-bioturbated sediments of Cariaco Basin are the direct result of large regional changes in rainfall and trade wind strength, driven by seasonal shifts in the position of the Intertropical Convergence Zone (ITCZ; Fig. 1) and its associated convection (Peterson et al., 2000; Haug et al., 2001). Lightcolored laminae consist mostly of biogenic components deposited during the dry winter-spring upwelling season when the ITCZ is located at its southernmost position and trade winds along the Venezuelan coast are strong. In contrast, dark laminae are deposited during the summer-fall rainy season when the ITCZ migrates to its most northerly position, nearly above Cariaco Basin. Individual dark laminae are rich in terrigenous grains and contain higher quantities of titanium (Ti) and other lithophilic elements. Our interpretation of bulk 